\title{
Evaluation of four molecular methods for the diagnosis of tuberculosis in pulmonary and blood samples from immunocompromised patients
}

\author{
Juliana Maria Azevedo de Lyra ${ }^{1 /+}$, Magda Maruza², Mirela Verza ${ }^{3}$, Maria Madileuza Carneiro ${ }^{4}$, \\ Maria de Fátima Militão de Albuquerque ${ }^{5}$, Maria Lúcia Rossetti ${ }^{3,6}$, Ricardo Ximenes ${ }^{7}$, \\ Maria Cynthia Braga ${ }^{8}$, Norma Lucena-Silva ${ }^{1}$
}

\begin{abstract}
${ }^{1}$ Departamento de Imunologia ${ }^{5}$ Departamento de Saúde Pública ${ }^{8}$ Departamento de Parasitologia, Centro de Pesquisas Aggeu MagalhãesFiocruz, Recife, PE, Brasil ${ }^{2}$ Hospital Correia Picanço ${ }^{4}$ Laboratório Central de Pernambuco, Secretaria do Estado de Pernambuco, Recife, PE, Brasil ${ }^{3}$ Fundação Estadual de Produção e Pesquisa em Saúde, Porto Alegre, RS, Brasil ${ }^{6}$ Universidade Luterana do Brasil, Porto Alegre, RS, Brasil ' Departamento de Medicina Tropical, Universidade Federal de Pernambuco, Recife, PE, Brasil
\end{abstract}

The present study analysed the concordance among four different molecular diagnostic methods for tuberculosis (TB) in pulmonary and blood samples from immunocompromised patients. A total of 165 blood and 194 sputum samples were collected from 181 human immunodeficiency virus (HIV)-infected patients with upper respiratory complaints, regardless of suspicious for TB. The samples were submitted for smear microscopy, culture and molecular tests: a laboratory-developed conventional polymerase chain reaction (PCR) and real-time quantitative PCR $(q P C R)$ and the Gen-Probe and Detect-TB Ampligenix kits. The samples were handled blindly by all the technicians involved, from sample processing to results analysis. For sputum, the sensitivity and specificity were $100 \%$ and 96.7\% for qPCR, 81.8\% and $94.5 \%$ for Gen-Probe and $100 \%$ and $66.3 \%$ for Detect-TB, respectively. qPCR presented the best concordance with sputum culture [kappa $(k)=0.864)]$, followed by Gen-Probe $(k=0.682)$. For blood samples, qPCR showed $100 \%$ sensitivity and $92.3 \%$ specificity, with a substantial correlation with sputum culture $(k=$ $0.754)$ and with the $q P C R$ results obtained from sputum of the corresponding patient $(k=0.630)$. Conventional PCR demonstrated the worst results for sputa and blood, with a sensitivity of $100 \%$ vs. $88.9 \%$ and a specificity of $46.3 \%$ vs. $32 \%$, respectively. Commercial or laboratory-developed molecular assays can overcome the difficulties in the diagnosis of TB in paucibacillary patients using conventional methods available in most laboratories.

Key words: tuberculosis - paucibacillary - Gen-Probe - Detec-TB - real-time PCR

The diagnosis of tuberculosis (TB) remains based on direct examination and solid cultures in the majority of countries with high TB prevalence (Smith et al. 1996, Chan et al. 2000, Silva et al. 2012, Nakiyingi et al. 2013). Frequently, among paucibacillary patients such as children, human immunodeficiency virus (HIV) co-infected patients and patients with the extrapulmonary form of TB (regardless of age), smear-based microscopy is negative and the sputum-culture sensitivity is low (Bollela et al. 1999, Burroughs et al. 1999, Pai et al. 2004). The use of molecular biology techniques has increased the ability to diagnose TB in paucibacillary TB (Almeda et al. 2000, Portillo-Gómez et al. 2000, Al Zahrani et al. 2001, Boehme et al. 2011, Lawn et al. 2013) and has also shortened the time of diagnosis in relation to culturing in solid media, from four-six weeks to 24-48 h (Richeldi et al. 1995, Kivihya-Ndugga et al. 2004, Hida et al. 2012). The World Health Organization (WHO 2008) conducted a comparative analysis of 19 different commercial kits for the

doi: $10.1590 / 0074-0276130542$

+ Corresponding author: juli_lyra@hotmail.com

Received 17 November 2013

Accepted 20 June 2014 molecular diagnosis of TB, using the standard protocol for each test and considering endemic and non-endemic countries. The results demonstrated a mean sensitivity of $27 \%$ and specificity greater than $90 \%$ in only $30 \%$ of the tests. In that study, TB-HIV co-infection reduced test performance, regardless of whether TB was endemic to the country. The Gen-Probe Amplified-MTD Direct Test kit was the first test for detecting DNA of the Mycobacterium tuberculosis complex to gain approval from the Food and Drug Administration (FDA) (Vlaspolder et al. 1995).

Xpert MTB/RIF (Cepheid, USA) is the first fully automated assay based on hemi-nested real-time polymerase chain reaction (PCR) for the detection of TB and rifampicin resistance performed directly on untreated sputum, with results obtained in less than $2 \mathrm{~h}$. The assay was approved by the WHO in 2010 (Lawn et al. 2013, Nakiyingi et al. 2013).

COBAS $^{\circledR}$ Amplicor is a commercial test based on amplification, hybridisation and detection of the mycobacteria multicopy IS6110 insertion element that also has been approved by the FDA (McAdam et al. 1990, Thierry et al. 1990, Almeda et al. 2000, Huyen et al. 2013). The Detect-TB Ampligenix Biotech Company kit is a test in the pre-clinical stage of development, which associates the amplification of the mycobacteria IS6110 sequence with the reversed hybridisation of the amplification product with probes complementary to internal 
sequences of the PCR-product, previously immobilised on microplates (Sperhacke et al. 2004, O'Donnell et al. 2012). In the present study, we analysed the concordance of the Gen-Probe, Detect-TB, conventional homemade PCR and real-time PCR tests on pulmonary and blood samples from immunocompromised patients with upper respiratory complaints.

\section{SUBJECTS, MATERIAL AND METHODS}

In total, 165 blood and 194 sputum samples were collected from 181 different HIV-positive patients with upper respiratory complaints, regardless of TB suspicions, who were attended at the Correia Picanço Hospital and Oswaldo Cruz University Hospital, as shown in Fig. 1. The samples were forwarded to Pernambuco Central Laboratory (LACEN-PE), where three unprocessed $0.5 \mathrm{~mL}$-aliquots of sputum were transferred into sterile microtubes, inside a biosafety cabinet located in the mycology laboratory to assure no cross-contamination with cultivated Mycobacterium. Unprocessed sputumaliquots and corresponding-patient blood samples were then forwarded to the molecular biology laboratory at Institute of Integrative Medicine Prof. Fernando Figueira (IMIP) for molecular testing. The remaining sputum samples underwent smear microscopy and culturing at the reference laboratory for TB diagnosis accredited by the Brazilian Ministry of Health located in the LACENPE. All samples were handled blindly by all technicians involved, from sample processing to results analysis.

Microbiological analysis - Acid-fast bacilli were detected by means of Ziehl-Neelsen staining on sputa smears. Sputa were decontaminated in accordance with the Petroff method and aliquots of $0.1 \mathrm{~mL}$ were placed in Lowenstein-Jansen solid medium. Blood samples did not undergo microbiological testing.

Genomic DNA extraction - The patients' blood samples underwent Ficoll-Paque Plus (GE Healthcare BioSciences AB, Sweden) fractioning for leucocyte isola-

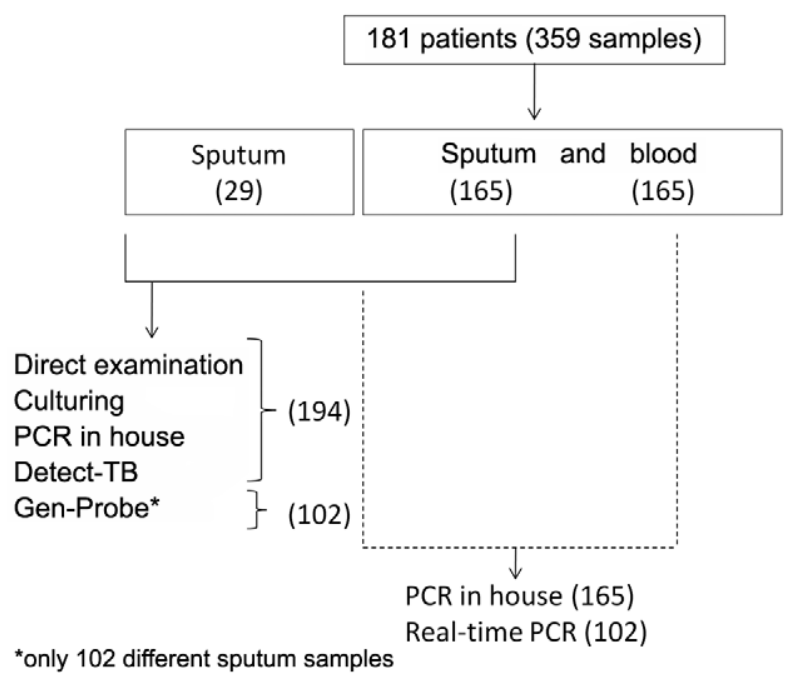

Fig. 1: flowchart of clinical specimens tested for tuberculosis diagnosis. PCR: polymerase chain reaction. tion. An aliquot of $10^{6}$ leucocytes and the first of the three sputum aliquots underwent genomic DNA extraction using proteinase $\mathrm{K}$ protocol. Briefly, the material was suspended in a $400 \mu \mathrm{L}$ lysozyme solution $(1.25 \mathrm{mg} /$ $\mathrm{mL}$ ) and was incubated at $37^{\circ} \mathrm{C}$ for $16 \mathrm{~h}$. Then, $75 \mu \mathrm{L}$ of proteinase $\mathrm{K}(20 \mathrm{mg} / \mathrm{mL})$ and $10 \%$ sodium dodecyl sulfate solution were added and the mixture was incubated at $65^{\circ} \mathrm{C}$. Next, $100 \mu \mathrm{L}$ of $5 \mathrm{M} \mathrm{NaCl}$ and $100 \mu \mathrm{L}$ of $\mathrm{CTAB} / \mathrm{NaCl}$ were added and the samples were incubated at $65^{\circ} \mathrm{C}$. After $10 \mathrm{~min}$ of incubation, the DNA was extracted with phenol/chloroform solution and then concentrated by means of precipitation with isopropanol. The DNA precipitate was obtained through centrifugation at $16,000 \mathrm{~g}$ in a microcentrifuge, washed with $70 \%$ ethanol and dissolved in $50 \mu \mathrm{L}$ of sterile water.

Conventional PCR - First, the genomic DNA underwent PCR for amplification of a target sequence on human DNA, acting as a positive control for the DNA extraction, thereby ensuring the absence of PCR inhibitors in the reaction. Next, PCR was performed with specific primers for amplification of the mycobacteria IS6110 genetic element. The total reaction volume was $50 \mu \mathrm{L}$ and included $1.5 \mathrm{mM}$ of $\mathrm{MgCl}_{2}, 25 \mathrm{pmol}$ of each primer (sense: 5'cgagctgcgegatggcgaac and antisense: 5 'taggtgctggtggtccgaag, synthesised by Invitrogen, USA), $200 \mu \mathrm{M}$ of each dNTP and 1.25 units of DNA polymerase (Invitrogen). The reaction conditions were one cycle of $96^{\circ} \mathrm{C}$ for $3 \mathrm{~min}, 30$ cycles of $96^{\circ} \mathrm{C}$ for $30 \mathrm{~s}$ for denaturation, $65^{\circ} \mathrm{C}$ for $30 \mathrm{~s}$ for annealing, $72^{\circ} \mathrm{C}$ for $30 \mathrm{~s}$ for extension and, finally, a cycle of $7 \mathrm{~min}$ at $72^{\circ} \mathrm{C}$ using a thermocycler (Gradient Eppendorf, Germany). The PCR product was visualised on $2.5 \%$ agarose gel under ultraviolet light. The reaction was considered positive when the ethidium bromide-stained band corresponded to $245 \mathrm{bp}$.

Real-time PCR - Quantitative PCR (qPCR) was performed using the same set of primers for IS6110 amplification as used in conventional PCR and an internal probe (Applied Biosystems, USA) in the presence of the TaqMan ${ }^{\circledR}$ Universal PCR Master Mix and the DNA extracted from the patients' sputum or blood. The conditions for amplification of the IS6110 element were as follows: denaturation for $15 \mathrm{~min}$ at $95^{\circ} \mathrm{C}$ followed by 45 cycles of $15 \mathrm{~s}$ at $94^{\circ} \mathrm{C}$ and $60 \mathrm{~s}$ at $60^{\circ} \mathrm{C}$. In all PCR runs, standard curves were obtained using plasmid DNA encompassing the mycobacteria IS6110 sequence as the reaction positive control and all samples were tested in duplicate. Reaction with no DNA added was used as the negative control, also in duplicate. The reaction was run in an ABI 7500 machine with setup for absolute quantification, using a standard curve prepared with serial 10X dilution from $10 \mathrm{ng}$ [cycle threshold $(\mathrm{Ct})=14$ ] to 100 $\mathrm{fg}(\mathrm{Ct}=37)$ of plasmid control DNA in triplicate. The efficiency of the amplification reaction was 1.8 , with a threshold set at 0.02 based on data from 26 different experiments. The slope was -3.84 and $\mathrm{R}=0.999$.

Detect-TB - The second sputum aliquot was tested for the presence of mycobacteria genome using the Detect-TB Ampligenix Biotech Company kit (Belo Hori- 
zonte, Brazil). Briefly, the cells were lysed to release the genomic DNA and to make it soluble. The extracted DNA was purified by means of silica resin capture in the presence of chaotropic agents, followed by successive washings and elution in a low-ionic-strength solution. Purified DNA underwent the IS6110 sequence amplification, using specific biotinylated primers. The PCR product was transferred into polystyrene microplates covalently immobilised with IS6110-probe. PCR product-bounded to the IS6110 immobilised probe was detected using a streptavidin-peroxidase/tetramethylbenzidine colorimetric system. Readings within the absorbance range from $0.225-0.275$ were considered to be indeterminate. Values below 0.225 were considered to be negative and above 0.275 as positive.

Gen-Probe amplified MTD - The third frozen stored sputum aliquot underwent the Gen-Probe amplified MTD (San Diego, USA) testing. Firstly, the $500 \mu \mathrm{L}$ samples were defrosted at room temperature (RT) in a biological cabinet. Then, the same volume of purifying solution of $2.9 \%$ sodium citrate and $4 \% \mathrm{NaOH}$ was added and incubated for $15 \mathrm{~min}$ at RT. The samples were neutralised by adding $500 \mu \mathrm{L}$ of phosphate buffer solution ( $\mathrm{pH}$ 6.8). The volume of the samples was adjusted to $450 \mu \mathrm{L}$ by centrifugation. All reagents and equipment used in the Gen-Probe protocol were as recommended by the manufacturer. Laboratory personnel trained by the company performed the protocol.

Quality control - The flux and transport of the biological samples between the different institutions involved in this project was carefully planned. The flux began in two public reference hospitals for HIV-infection treatment. These hospitals had a transport flow from their labs to the LACEN-PE, which is responsible for TB diagnosis in PE. The main problem was identifying the samples related to this research among the routine samples and therefore, we created small colourful forms to send with the research samples, working with the personnel of the LACEN-PE to identify the samples related to this study, to avoid processing exams in duplicate and possible specimen loss and to shorten the time of sample retention at the laboratory reception.

Another potential problem was related to where and how to aliquot the samples for the different tests. From the outset, we had decided to use the same samples for all tests given the possibility of different samples having different bacterial loads even when they are collected on the same sample day and the high likelihood that patients would not return on the second day to bring the first-daily sputum. To avoid possible cross-contamination with cultivated bacteria in the Mycobacterium facilities, the sputum samples were sent to the mycology lab because primarily manipulation was performed inside a biological cabinet in that laboratory after working hours. Three $0.5 \mathrm{~mL}$-aliquots were prepared from each sputum specimen, which were frozen and sent to the molecular biology laboratory at another institution under refrigeration; the remaining sputa were sent to the mycobacteria facilities at LACEN$\mathrm{PE}$ for microbiological analysis. Blood samples were sent to the molecular laboratory without manipulation.
All DNA extractions were performed at the Molecular Biology Laboratory of IMIP, inside a biosafety cabinet located in a room with restricted use to clinic sample handling. The PCR reactions were prepared in another room specifically designed for this purpose, free of biological samples and also inside a biosafety cabinet. The hybridisation procedures and the analysis of PCR products in gel were performed in the main area of the molecular biology laboratory.

For every conventional or real-time PCR run, two negative controls were run: one reaction was performed without the DNA template and another included genomic DNA of a healthy individual to identify possible nonspecific DNA amplification.

To avoid interpretation bias, the research teams at the hospitals, LACEN-PE and the Molecular Biology Laboratory at IMIP, were different and the samples received a number at the hospital, a different number at LACEN-PE and yet another at the Molecular Biology laboratory. All patient identification numbers were noted in the patient database at the Molecular Biology laboratory; however, the codes were only broken for analysis at the end of the cohort study.

Statistical analysis - The sensitivity, specificity and the positive and negative predictive values (NPV) for each of the molecular tests evaluated for the diagnosis of TB in HIV-infected patients were calculated considering sputum culture as the gold standard, using a $2 \times 2$ table. The concordance between tests was evaluated using the kappa (k) test (Epi Info v.6.04 software). The receiver operating characteristic (ROC) curves were performed using MedCalc software, Ostend, Belgium.

Ethics - The Aggeu Magalhães Research Centre Institutional Review Board approved this study under the registration CAAE: 0007.0.095.000-07. The authors declare no conflict of interest and do not have a direct financial relation with the commercial identity mentioned in this manuscript.

\section{RESULTS}

Sputum samples - Among 194 sputum samples from 181 different HIV-infected patients, 19 were culturepositive for M. tuberculosis, of which only eight were smear-positive.

Comparing the ROC curves of the different tests with sputum culture as the reference, the best results were associated with qPCR methodology (Fig. 2A). qPCR presented $100 \%$ sensitivity, $96.7 \%$ specificity, $78.6 \%$ positive predictive value (PPV), $100 \%$ NPV and $97 \%$ accuracy (Table I). qPCR results demonstrated excellent concordance with culture $(\mathrm{k}=0.864)$ and moderate concordance with Gen-Probe results $(\mathrm{k}=0.586)$ (Table II). The $\mathrm{Ct}$ average of culture-positive, smear-positive sputa (32.5; range, 24.4-36.4) was similar to culture-positive, smear-negative sputa (33.4; range 30.3-35.4). Three samples presented culture-negative and positive-qPCR results, with Ct of 18,19 and 21 .

Gen-Probe presented the second-best results with $81.8 \%$ sensitivity, $94.5 \%$ specificity, $64.3 \%$ PPV, $97.7 \%$ NPV and 93\% accuracy. A substantial concordance between GenProbe and culture results was observed $(\mathrm{k}=0.682)$ 
Detect-TB demonstrated a sensitivity of $100 \%$, but a specificity of $66.3 \%$, corresponding to a PPV of $24.4 \%$. ROC curves constructed with different cut-off values for testing Detect-TB showed that the best results for sensitivity and specificity occurred with a cut-off of $300(100 \%$ sensitivity, $67.4 \%$ specificity) and $275(100 \%$ sensitivity, $66.3 \%$ specificity). In this study, the cut-off used was 275 , which was indicated by the manufacturer (Fig. 2B). However, higher cut-off values might improve specificity with some compromised of sensitivity.

The lowest specificity was associated with conventional PCR performed from sputum (46.3\%) and blood (32\%) samples (Table I).

Blood samples - Concerning the molecular tests performed on the patients' blood samples, we only took into consideration samples from patients for whom sputum also had been collected for definition of the TB cases based on sputum culture.
Regarding blood samples, qPCR showed $100 \%$ sensitivity, $92.3 \%$ specificity, $61.1 \%$ PPV and $100 \%$ NPV in comparison to the sputum culture, whereas the in-house PCR showed sensitivity and specificity values of $88.9 \%$ and $32 \%$, respectively (Fig. 2C). A substantial concordance was observed between qPCR results obtained from blood and positive culture on sputum $(\mathrm{k}=0.754)$ and also between qPCR results from blood and sputa $(\mathrm{k}$ $=0.630)$ (Table II).

\section{DISCUSSION}

Many studies on the accuracy of molecular assays have been published on the diagnosis of pulmonary and non-pulmonary TB, both associated with smear-positive or smear-negative sputum samples and in HIV-infected or non-infected patients (Peter et al. 2012, Lawn et al. 2013, Theron et al. 2013, Walusimbi et al. 2013, Raizada et al. 2014).
A

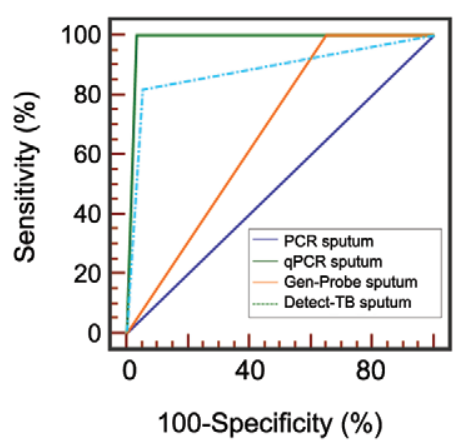

\begin{tabular}{|l|c|c|}
\hline & Sensitivity (\%) & Specificity (\%) \\
\hline PCR & 100 & 46.3 \\
\hline qPCR & 100 & 96.7 \\
\hline Detect-TB & 100 & 66.3 \\
\hline Gen-Probe & 81.8 & 94.5 \\
\hline
\end{tabular}

B

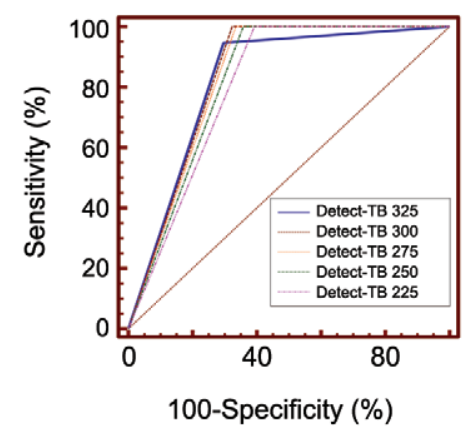

\begin{tabular}{|l|c|c|}
\hline Cut-off & Sensitivity (\%) & Specificity (\%) \\
\hline Detect-TB 325 & 94.7 & 70.3 \\
\hline Detect-TB 300 & 100 & 67.4 \\
\hline Detect-TB 275 & 100 & 66.3 \\
\hline Detect-TB 250 & 100 & 64 \\
\hline Detect-TB 225 & 100 & 60.6 \\
\hline
\end{tabular}

C

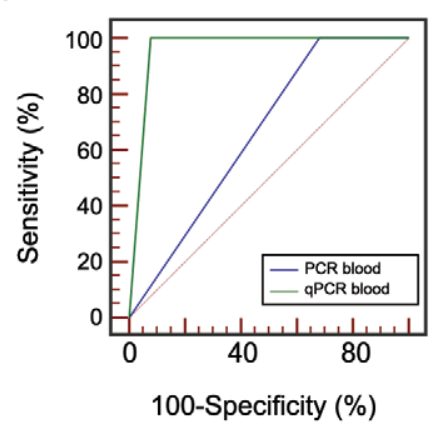

\begin{tabular}{|l|c|c|}
\hline & Sensitivity (\%) & Specificity (\%) \\
\hline PCR & 88.9 & 32 \\
\hline qPCR & 100 & 92.3 \\
\hline
\end{tabular}

Fig. 2: receiver operating characteristic curve accuracy for molecular assay in tuberculosis (TB). A: accuracy estimated for four different molecular assays for TB testing in sputa using culture as gold-standard; B: accuracy of different cut-off set for TB testing in sputa using the DetectTB assay; C: accuracy of conventional e quantitative polymerase chain reaction (qPCR) for TB diagnosis in blood.

TABLE I

Positive (PPV) and negative (NPV) predictive values, sensitivity and specificity in samples using different molecular methods for the diagnosis of tuberculosis (TB) and sputum culture as gold standard

\begin{tabular}{lccccc}
\hline $\begin{array}{l}\text { Reference x tests } \\
\text { (sample) }\end{array}$ & $\mathrm{n}$ & $\begin{array}{c}\text { PPV } \\
(\%)\end{array}$ & $\begin{array}{c}\text { NPV } \\
(\%)\end{array}$ & $\begin{array}{c}\text { Sensitivity } \\
(\%)\end{array}$ & $\begin{array}{c}\text { Specificity } \\
(\%)\end{array}$ \\
\hline Culture x PCR (sputum) & 194 & $16.81(9.4-29.5)$ & $100(88.8-100)$ & $100(67.9-100)$ & $46.3(32.7-53.7)$ \\
Culture x qPCR (sputum) & 102 & $78.60(48.8-94.3)$ & $100(94.8-100)$ & $100(67.9-100)$ & $96.70(90-99.1)$ \\
Culture x Detect-TB (sputum) & 194 & $24.36(12.2-37)$ & $100(91.6-100)$ & $100(67.9-100)$ & $66.30(47.4-68.3)$ \\
Culture x Gen-Probe (sputum) & 102 & $64.30(35.6-86)$ & $97.70(91.3-99.6)$ & $81.80(47.8-96.8)$ & $94.50(87.1-98)$ \\
Culture x PCR (blood) & 165 & $13.8(8.3-21.7)$ & $95.9(89.9-99.3)$ & $88.90(63.9-98.3)$ & $32(24.7-40.2)$ \\
Culture x qPCR (blood) & 102 & $61.1(36.1-81.7)$ & $100(94.6-100)$ & $100(67.9-100)$ & $92.30(84.3-96.6)$ \\
\hline
\end{tabular}

Detect-TB is a test in developing and Gen-Probe a commercial molecular test for TB diagnosis. Blood and sputum samples were collected on the same day. PCR: in house polymerase chain reaction; qPCR: quantitative real-time PCR. 
TABLE II

Concordance between microbiological and molecular tests for diagnosis of tuberculosis (TB)

\begin{tabular}{lccccc}
\hline Tests (sample) & $\mathrm{n}$ & Agreement & Kappa & $\mathrm{Z}$ & $\mathrm{p}$ \\
\hline Culture X PCR (sputum) & 194 & 0.490 & 0.139 & 2.76 & 0.0029 \\
Culture X qPCR (sputum) & 102 & 0.971 & 0.864 & 8.80 & 0.0000 \\
Culture X Detect-TB (sputum) & 194 & 0.628 & 0.231 & 3.65 & 0.0002 \\
Culture X Gen-Probe (sputum) & 102 & 0.931 & 0.682 & 6.95 & 0.0000 \\
Culture X PCR (blood) & 165 & 0.382 & 0.062 & 1.83 & 0.0337 \\
Culture X qPCR (blood) & 102 & 0.931 & 0.754 & 7.59 & 0.0000 \\
PCR (sputum) X qPCR (sputum) & 102 & 0.520 & 0.179 & 3.17 & 0.0007 \\
PCR (sputum) X Detect-TB (sputum) & 102 & 0.647 & 0.301 & 3.15 & 0.0008 \\
PCR (sputum) X Gen-Probe (sputum) & 102 & 0.480 & 0.112 & 1.99 & 0.0236 \\
qPCR (sputum) X Detect-TB (sputum) & 102 & 0.657 & 0.294 & 4.19 & 0.0000 \\
qPCR (sputum) X Gen-Probe (sputum) & 102 & 0.902 & 0.586 & 5.92 & 0.0000 \\
PCR (blood) X qPCR (blood) & 102 & 0.461 & 0.157 & 2.95 & 0.0016 \\
qPCR (sputum) X qPCR (blood) & 102 & 0.902 & 0.630 & 6.44 & 0.0000 \\
\hline
\end{tabular}

Detect-TB is a test in developing and Gen-Probe a commercial molecular test for TB diagnosis. Blood and sputum samples were collected on the same day. Culture was performed only in sputa. PCR: in house polymerase chain reaction; qPCR: quantitative real-time PCR.

Smear-based microscopy is the most commonly used approach for pulmonary TB detection, demonstrating $70 \%$ sensitivity compared with culture associated with a clinical definition of the disease as the gold standard; however, in HIV-infected patients the smearbased sensitivity might be lower than $40 \%$ (Boehme et al. 2011, Lawn et al. 2011, Scherer et al. 2011). In our study, the smear-based sensitivity was $42 \%$. This was mainly related to the low bacillary load in sputum from HIV-infected patients (O'Grady et al. 2012).

We observed a great variation in the accuracies of the four tests evaluated considering that all were PCR-based assays and all used samples obtained from the same sputum. qPCR demonstrated superior performance with 97\% accuracy, followed by Gen-Probe (93\%), Detect-TB (70\%) and conventional PCR (52\%) for the detection of pulmonary TB infection from sputum. Recent publications regarding the molecular detection of pulmonary TB in HIV-infected patients also have shown variations in assay sensitivity (53-100\%) between different or even the same assay (Table III).

For TB detection in sputum, our qPCR assay presented $100 \%$ sensitivity and $96.7 \%$ specificity, comparable to the sensitivity of $80-95 \%$ and the specificity of $95-100 \%$ reported by others who also developed the TaqMan assay for detection of the IS6110 element (Gomez et al. 2011, Lira et al. 2013, Albuquerque et al. 2014). qPCR was positive for $100 \%$ of the smear-negative, culture-positive patients, providing earlier TB diagnosis for more TBsuspected patients than smear-based microscopy ( $7 \%$ vs. $4 \%)$ in HIV-infected patients. Improvement in pulmonary TB detection (25\%) by means of molecular assay was reported in Chile, a TB non-endemic area, confirming the power of molecular tools in TB diagnosis for TBcontrol programs (Balcells et al. 2012). Three patients with false-positive qPCR from sputum received empirical treatment for TB within six months of being tested and the clinical-symptom improvement confirmed their disease status. The withdrawal of a considerable (1.5 $\mathrm{mL}$ ) amount of sputum for molecular analysis prior to sputum culturing might explained the absence of acidfast bacillary growth on solid media, likely due to the loss of bacillary viability as a consequence of the sputum decontamination procedure (Michelon et al. 2011).

The sensitivity and specificity of the Gen-Probe assay as reported in the literature ranges from $92-100 \%$ and from $85-100 \%$, respectively, but in HIV-positive patients the sensitivity might be lower than $42 \%$ (Syre et al. 2009, Davis et al. 2011, Papaventsis et al. 2012, Roberts et al. 2012). In our study, the performance of Gen-Probe was similar to qPCR (93\% vs. $97 \%$ accuracy), with $81.8 \%$ sensitivity and $94.5 \%$ specificity for TB detection in sputum. Five false-positive cases were observed, two of whom received empirical TB treatment with improvement in clinical symptoms. In contrast to the qPCR assay, the Gen-Probe assay was associated with two false-negative cases, possibly due to the insufficient target DNA in the $0.5 \mathrm{~mL}$ sputum aliquot used, considering that the Gene-Probe protocol recommends the collection of 10 $\mathrm{mL}$ of sputum for decontamination and concentration procedures prior to use. The presence of PCR inhibitors in the sample may also have induced false-negative reactions with the Gen-Probe assay, which were not observed in the qPCR assay because, in this latter case, DNA was extracted using proteinase $\mathrm{K}$ digestion followed by a purification step performed with phenol-chloroform.

Cases identified as false-positives by the Detect-TB assay were responsible for the low specificity $(66.3 \%)$ and PPV (24.4\%) observed in our study. The causes for this performance are not clear, because a sensitivity of 


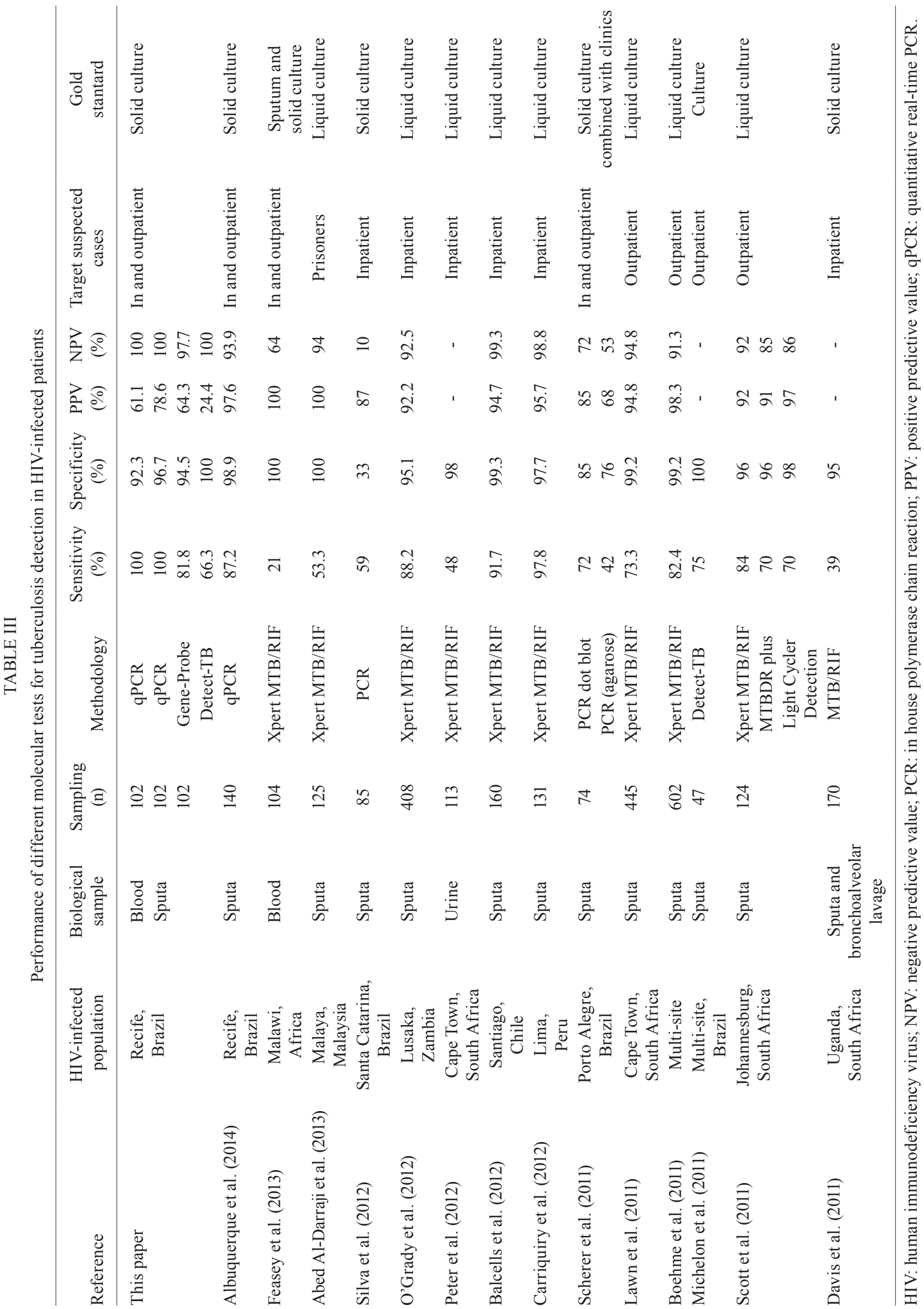


$75 \%$ and a specificity of $100 \%$ were reported using the same assay for TB detection in spontaneous sputum samples obtained from patients suspected of having TB (Michelon et al. 2011). Difficulties in handling the kit, reagents' stability and delays in reading the reaction were considered. The handling was performed exclusively by laboratory personnel that had received training in executing the Detect-TB protocol. To read the samples, we placed the microplates on a cold surface to transport them to another laboratory in a connected building and thus some delay in reading might have contributed to these results, although we also should consider that some of these false-positive cases might indeed have been positive cases that had not been identified by culturing.

Our conventional PCR assay showed the poorest performance in sputum with $46.3 \%$ specificity. A published meta-analysis demonstrated a sensitivity variation of $32-92 \%$ with a mean of $72 \%$ and a specificity variation of $93-100 \%$ with a mean of $96 \%$ for the PCR simplex methodology for TB detection, in comparison with sputum culture results and clinical criteria (Sarmiento et al. 2003). In our study, we used only culture as the gold standard. Nevertheless, the fact that qPCR and conventional PCR results were so divergent surprises us because both assays used the same primers and sample processing. The main differences were (i) qPCR used a fluorescent internal probe for accuracy improvement, which per se justifies this finding, while the conventional PCR did not have the probe hybridisation step, (ii) samples were run in duplicate or triplicate in qPCR, whereas a single sample normally was run for conventional PCR and (iii) qPCR data were measurable and positive cases were defined based on a standard curve, whereas in conventional PCR, the results were based on the identification of a band in agarose gel corresponding in size to the amplified PCR product. For all these reasons, the conventional PCR test may not be reliable (Al Zahrani et al. 2001, Chakravorty et al. 2005).

The difference in sample processing is a limitation for comparative analysis of the accuracy of different molecular assays for TB diagnosis. A study on the performance of the Xpert MTB/RIF test with an IS6110TaqMan qPCR assay for the detection of mycobacteria in respiratory specimens processed by the standard procedure of decontamination and centrifugation reported no differences in overall sensitivity $(79 \%$ vs. $84 \%$, respectively) of both tests, which presented $100 \%$ sensitivity for smear-positive sputum, with no differences observed in smear-negative sputum sensitivity ( $57 \%$ vs. $68 \%$, respectively) (Armand et al. 2011). Alternatively, Park et al. (2013) compared the performance of the Xpert MTB/RIF test using $1 \mathrm{~mL}$ of non-processed respiratory specimens with the COBAS TaqMan MTB assay using decontaminated-concentrated respiratory specimens obtained from $\sim 5 \mathrm{~mL}$ sputum. The performance of both assays using culture results as the gold standard showed that the overall sensitivities of the Xpert $(67.9 \%)$ and COBAS (71.4\%) assays were similar. The Xpert sensitivity did not significantly differ between smear-positive and smear-negative (67\% vs. 69\%) sputum; however, the reduction from the $87 \%$ sensitivity in smear-positive sputum to $54 \%$ sensitivity in smear-negative spu- tum observed with the COBAS assay suggested that the sputum-decontamination processing included in the COBAS protocol contributed to reducing the bacillary viability in culture, even though the proportional sputum volume used was larger than that used in the Xpert test (Park et al. 2013).

Comparing the performance of qPCR from sputum and blood samples of corresponding patients, the qPCR test exhibited an accuracy of $93 \%$ for the detection of TB in blood, showing good concordance with culture results $(75 \%)$ and the qPCR results from sputum (63\%). One explanation for this higher concordance with sputum culture than with qPCR testing of sputum was the high sensitivity of the qPCR test in sputum in relation to culture. The three cases of negative-culture and positive-qPCR results obtained from sputum were also negative-qPCR for blood, suggesting that mycobacteraemia might be associated with advanced disease. In this context, published data on the Xpert test for TB detection in blood revealed a $21 \%$ sensitivity and $100 \%$ specificity compared with sputum culture ( $56 \%$ concordance), but a positive association was reported between positive Xpert assay from blood samples and the mortality rate in HIV-infected patients (Feasey et al. 2013). The main difference between the Xpert study and our protocol was in sample processing: we used leukocytes purified from $5 \mathrm{~mL}$ peripheral blood, whereas the Xpert protocol requires the collection of 18 $\mathrm{mL}$ of peripheral blood for cellular lyses and concentration into a $1 \mathrm{~mL}$ sample for introduction into the Xpert cartridge for diagnosis. In this context, it is noteworthy that blood components such as haem, lactoferrin and immunoglobulin G have been associated with reduced amplification yield (Al-Soud et al. 2000, Al-Soud \& Rådström 2001) and the efficient removal of PCR-inhibitors from blood-extracted DNA contributes to improved sensitivity of the PCR-based diagnostic assay.

In HIV-infected patients, confirmation of the diagnosis of pulmonary TB from sputum is more difficult due to the low bacillary load in sputum and this difficulty is also associated with external factors that influence the sample quality, such as inadequate sputum collection, sample transportation, time delays in sample processing and the methodology employed. We believe that qPCR is one of the molecular tests that should be considered as a tool for the detection of pulmonary TB in smearnegative patients.

\section{REFERENCES}

Abed Al-Darraji HA, Abd Razak H, Ng KP, Altice FL, Kamarulzaman A 2013. The diagnostic performance of a single GeneXpert MTB/RIF assay in an intensified tuberculosis case finding survey among HIV-infected prisoners in Malaysia. PLoS ONE 8: e73717.

Al Zahrani K, Al Jahdali H, Poirier L, René P, Menzies D 2001. Yield of smear, culture and amplification tests from repeated sputum induction for the diagnosis of pulmonary tuberculosis. Int J Tuberc Lung Dis 5: 855-860.

Albuquerque YM, Lima AL, Lins AK, Magalhães M, Magalhães V 2014. Quantitative real-time PCR (q-PCR) for sputum smear diagnosis of pulmonary tuberculosis among people with HIV/ AIDS. Rev Inst Med Trop Sao Paulo 56: 139-142.

Almeda J, García A, González J, Quintó L, Ventura PJ, Vidal R, Rufí G, Martínez JA, de Anta MTJ, Trilla A, Alonso PL 2000. 
Clinical evaluation of an in-house IS6110 polymerase chain reaction for diagnosis of tuberculosis. Eur J Clin Microbiol Infect Dis 19: 859-867.

Al-Soud WA, Jo"nsson LJ, Rådström P 2000. Identification and characterization of immunoglobulin $\mathrm{G}$ in blood as a major inhibitor of diagnostic PCR. J Clin Microbiol 38: 345-350.

Al-Soud WA, Rådström P 2001. Purification and characterization of PCR-inhibitory components in blood cells. J Clin Microbiol 39: 485-493.

Armand S, Vanhuls P, Delcroix G, Courcol R, Lemaître N 2011. Comparison of the Xpert MTB/RIF test with an IS6110-TaqMan real-time PCR assay for direct detection of Mycobacterium tuberculosis in respiratory and non-respiratory specimens. J Clin Microbiol 49: 1772-1776.

Balcells ME, García P, Chanqueo L, Bahamondes L, Lasso M, Gallardo AM, Cifuentes L 2012. Rapid molecular detection of pulmonary tuberculosis in HIV-infected patients in Santiago, Chile. Int J Tuberc Lung Dis 16: 1349-1353.

Boehme CC, Nicol MP, Nabeta P, Michael JS, Gotuzzo E, Tahirli R, Gler MT, Blakemore R, Worodria W, Gray C, Huang L, Caceres T, Mehdiyev R, Raymond L, Whitelaw A, Sagadevan K, Alexander H, Albert H, Cobelens F, Cox H, Alland D, Perkins MD 2011. Feasibility, diagnostic accuracy and effectiveness of decentralised use of the Xpert MTB/RIF test for diagnosis of tuberculosis and multidrug resistance: a multicentre implementation study. Lancet 377: 1495-1505.

Bollela VR, Sato DN, Fonseca BA 1999. Problems in the standardization of the polymerase chain reaction for the diagnosis of pulmonary tuberculosis. Rev Saude Publica 33: 281-286.

Burroughs M, Beitel A, Kawamura A, Revai K, Ricafort R, Chiu K, Jacobs R, Riley L 1999. Clinical presentation of tuberculosis in culture-positive children. Pediatric Tuberculosis Consortium. Pediatr Infect Dis J 18: 440-446.

Carriquiry G, Otero L, González-Lagos E, Zamudio C, Sánchez E, Nabeta P, Campos M, Echevarría J, Seas C, Gotuzzo E 2012. A diagnostic accuracy study of Xpert®MTB/RIF in HIV-positive patients with high clinical suspicion of pulmonary tuberculosis in Lima, Peru. PLoS ONE 7: e44626.

Chakravorty S, Sen MK, Tyagi JS 2005. Diagnosis of extrapulmonary tuberculosis by smear, culture and PCR using universal sample processing technology. J Clin Microbiol 43: 4357-4362.

Chan ED, Heifets L, Iseman MD 2000. Immunologic diagnosis of tuberculosis: a review. Tuber Lung Dis 80: 131-140.

Davis JL, Huang L, Worodria W, Masur H, Cattamanchi A, Huber C, Miller C, Conville PS, Murray P, Kovacs JA 2011. Nucleic acid amplification tests for diagnosis of smear-negative TB in a high HIV-prevalence setting: a prospective cohort study. PLOS ONE 6: e16321.

Feasey NA, Banada PP, Howson W, Sloan DJ, Mdolo A, Boehme C, Chipungu GA, Allain TJ, Heyderman RS, Corbett EL, Alland D 2013. Evaluation of Xpert MTB/RIF for detection of tuberculosis from blood samples of HIV-infected adults confirms Mycobacterium tuberculosis bacteremia as an indicator of poor prognosis. J Clin Microbiol 51: 2311-2316.

Gomez DI, Mullin CS, Mora-Guzmán F, Crespo-Solis JG, FisherHoch SP, McCormick JB, Restrepo BI 2011. Rapid DNA extraction for specific detection and quantitation of Mycobacterium tuberculosis DNA in sputum specimens using Taqman assays. Tuberculosis (Edinb) 91 (Suppl. 1): S43-S48.

Hida Y, Hisada K, Shimada A, Yamashita M, Kimura H, Yoshida H, Iwasaki H, Iwano M 2012. Rapid detection of the Mycobacterium tuberculosis complex by use of quenching probe PCR (geneCube). J Clin Microbiol 50: 3604-3608.

Huyen MN, Tiemersma EW, Kremer K, de Haas P, Lan NT, Buu TN, Sola C, Cobelens FG, van Soolingen D 2013. Characterisation of Mycobacterium tuberculosis isolates lacking IS6110 in Vietnam. Int J Tuberc Lung Dis 17: 1479-1485.

Kivihya-Ndugga L, van Cleeff M, Juma E, Kimwomi J, Githui W, Oskam L, Schuitema A, van Soolingen D, Nganga L, Kibuga D, Odhiambo J, Klatser P 2004. Comparison of PCR with the routine procedure for diagnosis of tuberculosis in a population with high prevalences of tuberculosis and human immunodeficiency virus. J Clin Microbiol 42: 1012-1015.

Lawn SD, Brooks SV, Kranzer K, Nicol MP, Whitelaw A, Vogt M, Bekker LG, Wood R 2011. Screening for HIV-associated tuberculosis and rifampicin resistance before antiretroviral therapy using the Xpert MTB/RIF assay: a prospective study. PLoS Med 8: e1001067.

Lawn SD, Mwaba P, Bates M, Piatek A, Alexander H, Marais BJ, Cuevas LE, McHugh TD, Zijenah L, Kapata N, Abubakar I, McNerney R, Hoelscher M, Memish ZA, Migliori GB, Kim P, Maeurer M, Schito M, Zumla A 2013. Advances in tuberculosis diagnostics: the Xpert MTB/RIF assay and future prospects for a point-of-care test. Lancet Infect Dis 13: 349-361.

Lira LA, Santos FC, Carvalho MS, Montenegro RA, Lima JF, Schindler HC, Montenegro LM 2013. Evaluation of a IS6110-Taqman real-time PCR assay to detect Mycobacterium tuberculosis in sputum samples of patients with pulmonary TB. J Appl Microbiol 114: 1103-1108.

McAdam RA, Hermans PW, van Soolingen D, Zainuddin ZF, Catty D, van Embden JD, Dale JW 1990. Characterization of a Mycobacterium tuberculosis insertion sequence belonging to the IS3 family. Mol Microbiol 4: 1607-1613.

Michelon CT, Rosso F, Schmid KB, Sperhacke RD, Oliveira MM, Kritski AL, Rezende Jr L, Costa ERD, Ribeiro AW, Verza M, Cafrune PI, Silva MSN, Kuhleis D, Zaha A, Rossetti MLR 2011. Colorimetric microwell plate reverse-hybridization assay for Mycobacterium tuberculosis detection. Mem Inst Oswaldo Cruz 106: 194-199.

Nakiyingi L, Nankabirwa H, Lamorde M 2013. Tuberculosis diagnosis in resource-limited settings: clinical use of GeneXpert in the diagnosis of smear-negative PTB: a case report. Afr Health Sci 13: $522-524$.

O’Donnell N, Corcoran D, Lucey B, Barrett A 2012. Molecular-based mycobacterial identification in a clinical laboratory setting: a comparison of two methods. Br J Biomed Sci 69: 164-168.

O’Grady J, Bates M, Chilukutu L, Mzyece J, Cheelo B, Chilufya M, Mukonda L, Mumba M, Tembo J, Chomba M, Kapata N, Maeurer M, Rachow A, Clowes P, Hoelscher M, Mwaba P, Zumla A 2012. Evaluation of the Xpert MTB/RIF assay at a tertiary care referral hospital in a setting where tuberculosis and HIV infection are highly endemic. Clin Infect Dis 55: 1171-1178.

Pai M, Flores LL, Hubbard A, Riley LW, Colford Jr JM 2004. Nucleic acid amplification tests in the diagnosis of tuberculous pleuritis: a systematic review and meta-analysis. BMC Infect Dis 4: 6 .

Papaventsis D, Ioannidis P, Karabela S, Nikolaou S, Syridou G, Marinou I, Konstantinidou E, Amanatidou V, Spyridis N, Kanavaki S, Tsolia M 2012. Impact of the Gen-Probe Amplified MTD ${ }^{\circledR}$ Test on tuberculosis diagnosis in children. Int J Tuberc Lung Dis 16: 384-390.

Park KS, Kim JY, Lee JW, Hwang YY, Jeon K, Koh WJ, Ki CS, Lee NY 2013. Comparison of the Xpert MTB/RIF and COBAS TaqMan MTB assays for detection of Mycobacterium tuberculosis in respiratory specimens. J Clin Microbiol 51: 3225-3227. 
Peter JG, Theron G, Muchinga TE, Govender U, Dheda K 2012. The diagnostic accuracy of urine-based Xpert MTB/RIF in HIV-infected hospitalized patients who are smear-negative or sputum scarce. PLoS ONE 7: e39966.

Portillo-Gómez L, Morris SL, Panduro A 2000. Rapid and efficient detection of extra-pulmonary Mycobacterium tuberculosis by PCR analysis. Int J Tuberc Lung Dis 4: 361-370.

Raizada N, Sachdeva KS, Chauhan DS, Malhotra B, Reddy K, Dave PV, Mundade Y, Patel P, Ramachandran R, Das R, Solanki R, Wares DF, Sahu S, O’Brien R, Paramasivan CN, Dewan PK 2014. A multi-site validation in India of the line probe assay for the rapid diagnosis of multi-drug resistant tuberculosis directly from sputum specimens. PLOS ONE 9: e88626.

Richeldi L, Barnini S, Saltini C 1995. Molecular diagnosis of tuberculosis. Eur Respir J (Suppl. 20): S689-S700.

Roberts SA, Lowe O, Pandey S, Williamson DA, Newton S, Vaughan R 2012. Comparison of the MGIT TBc immunochromatographic assay with the Accuprobe Gen-Probe TB assay for identification of Mycobacterium tuberculosis complex: results from a low-burden tuberculosis setting. Diagn Microbiol Infect Dis 74: 415-416.

Sarmiento OL, Weigle KA, Alexander J, Weber DJ, Miller WC 2003. Assessment by meta-analysis of PCR for diagnosis of smear-negative pulmonary tuberculosis. J Clin Microbiol 41: 3233-3240.

Scherer LC, Sperhacke RD, Jarczewski C, Cafrune PI, Michelon CT, Rupenthal R, Ribeiro MO, Netto AR, Rossetti ML, Kritski AL 2011. Comparison of two laboratory-developed PCR methods for the diagnosis of pulmonary tuberculosis in Brazilian patients with and without HIV infection. BMC Pulm Med 11: 15.

Scott LE, McCarthy K, Gous N, Nduna M, Van Rie A, Sanne I, Venter WF, Duse A, Stevens W 2011. Comparison of Xpert MTB/ RIF with other nucleic acid technologies for diagnosing pulmonary tuberculosis in a high HIV prevalence setting: a prospective study. PLoS Med 8: e1001061.
Silva MR, Machado T, Bazzo ML 2012. Diagnosis of the pulmonary tuberculosis by polymerase chain reaction: a comparative study between HIV-positive and HIV-negative individuals. Braz J Microbiol 43: 261-265.

Smith KC, Starke JR, Eisenach K, Ong LT, Denby M 1996. Detection of Mycobacterium tuberculosis in clinical specimens from children using a polymerase chain reaction. Pediatrics 97: 155-160.

Sperhacke RD, Mello FC, Zaha A, Kritski A, Rossetti ML 2004. Detection of Mycobacterium tuberculosis by a polymerase chain reaction colorimetric dot-blot assay. Int J Tuberc Lung Dis 8: 312-317.

Syre H, Myneedu VP, Arora VK, Grewal HM 2009. Direct detection of mycobacterial species in pulmonary specimens by two rapid amplification tests, the Gen-Probe amplified Mycobacterium tuberculosis direct test and the genotype mycobacteria direct test. J Clin Microbiol 47: 3635-3639.

Theron G, Peter J, Meldau R, Khalfey H, Gina P, Matinyena B, Lenders L, Calligaro G, Allwood B, Symons G, Govender U, Setshedi M, Dheda K 2013. Accuracy and impact of Xpert MTB/RIF for the diagnosis of smear-negative or sputum-scarce tuberculosis using bronchoalveolar lavage fluid. Thorax 68: 1043-1051.

Thierry D, Cave MD, Eisenach KD, Crawford JT, Bates JH, Gicquel B, Guesdon JL 1990. IS6110, an IS-like element of Mycobacterium tuberculosis complex. Nucleic Acids Res 18: 188.

Vlaspolder F1, Singer P, Roggeveen C 1995. Diagnostic value of an amplification method (Gen-Probe) compared with that of culture for diagnosis of tuberculosis. J Clin Microbiol 33: 2699-2703.

Walusimbi S, Bwanga F, de Costa A, Haile M, Joloba M, Hoffner S 2013. Meta-analysis to compare the accuracy of GeneXpert, MODS and the WHO 2007 algorithm for diagnosis of smear-negative pulmonary tuberculosis. BMC Infect Dis 13: 507.

WHO - World Health Organization 2008. Global tuberculosis control - surveillance, planning, financing. Available from: who.int/tb/ publications/global_report/2008/en/. 